\title{
DERIVATION OF CRITERIA FOR IDENTIFYING LIGHTWEIGHT POTENTIAL - A LITERATURE REVIEW
}

\author{
Laufer, Felix; Roth, Daniel; Binz, Hansgeorg \\ University of Stuttgart
}

\begin{abstract}
Lightweight potential is a powerful indicator - but not as powerful as it could be. Current methods for analyzing a product's potential to be reduced in mass only deal with a few of the most important criteria for lightweight design. The amount of literature dealing with lightweight design is significant, yet it can help to understand these versatile criteria. Firstly, the literature on this topic will therefore be reviewed to derive a broad set of criteria used in contemporary lightweight design. Secondly, a further review will reveal the criteria used to derive lightweight potential. Subsequently, both sets will be compared to identify the missing criteria used for the derivation of lightweight potential. This will support designers in two ways. On the one hand, matching and combining both criteria sets will enable the most representative criteria for a particular design case to be chosen, thus leading to a more comprehensible derivation of lightweight potential. On the other hand, the combination set will provide a basis for designers and design teams to refine their understanding of their own motivations for conducting lightweight design.
\end{abstract}

Keywords: Lightweight design, Decision making, Design for X (DfX)

\section{Contact:}

Laufer, Felix

University of Stuttgart

IKTD

Germany

felix.laufer@iktd.uni-stuttgart.de 


\section{INTRODUCTION}

The focus of research in lightweight design has shifted toward the conceptual stage in the productdesign process over the past few decades. This conceptual stage provides significant design freedom, thus enabling the product designer to analyze mass-relevant product parts to be optimized (Friedrich, 2017). This consideration is often related to the assessment of different lightweight potentials. In this case, the way in which the term "lightweight potential" is viewed in literature is ambiguous.

On the one hand, lightweight potential describes the potential of a substitution of a certain shape, material or technology for a respective counterpart. When considering a substitution of a certain product component made of steel for carbon-fiber-reinforced plastic, for instance, carbon fiber has a high lightweight potential compared to steel (Zhu et al., 2018).

On the other hand, lightweight potential is also used with regard to the analysis of where the most promising mass reductions can be achieved in a given product (Albers et al., 2017). In this case, a high lightweight potential does not refer to a certain shape, material or technology that is being quantitatively compared to their respective counterparts. Here, the comparison is made between a current component mass and a set mass goal (target mass) for the component in question based on a set of different criteria (Posner et al., 2014; Albers et al., 2013; Laufer et al., 2018). The criterion "energy consumption" results in the energy-consuming spindle of a tooling machine having a higher lightweight potential than the static casing of the machine, therefore the spindle is the more suitable part for mass reduction (Laufer et al., 2018).

In the context of this second interpretation of the term "lightweight potential" (which is the interpretation used throughout this entire paper), a wide set of relevant criteria is required. This core set - which considers the different aspects of lightweight design (Kaspar et al., 2018) - enables the designer to select the most representative criteria suited to a particular lightweight-design scenario in order to derive individual lightweight potential.

\section{PROBlem STATEMENT AND GOAL}

The term "criterion" in engineering design is often used with different connotations. The Oxford English Dictionary (Soanes and Persall, 2005) defines "criterion" as being the "[...] standard or principle by which something is judged [...]". Consequently, in the lightweight-design context of this paper, "criterion" is used as the standard by which the potential of a design object (e.g. a product component) is assessed with regard to mass reduction. To be more precise, within this paper's context, "criterion" refers to a certain motivation for performing a lightweight optimization, which is thus referred to as a "motivational criterion". If the motivation for lightweight design is the reduction of the environmental impact of a product, for instance, the amount of $\mathrm{CO} 2$ emissions produced over the entire lifecycle might be an appropriate criterion for assessing the impact (Mayyas et al., 2017). If the motivation is to reduce the product's costs during use, fuel efficiency is one possible factor for assessing the reduction (Hottle et al., 2017). Furthermore, different motivations for lightweight design may occur simultaneously during the product-development process, thus yielding a wider set of diversified criteria. However, initial research studies have shown that there are discrepancies between the criteria currently used in literature for conducting lightweight design and the criteria used for deriving lightweight potential. This non-exhaustive criteria set can lead to an imprecise or even incorrect assessment of the lightweight potential.

The primary goal of this paper is to derive a broad set of criteria that can be used to derive lightweight potential. This set should support designers in choosing the most representative criteria for a particular design case as well as in refining the understanding of the motivation for conducting lightweight design. These considerations result in the following hypothesis: The number of versatile criteria existing in lightweight design is not comprehensively used for deriving lightweight potential. A twofold investigation should therefore be conducted which, on the one hand, examines criteria for lightweight design and, on the other hand, examines criteria used for deriving lightweight potential in the conceptual stage of the product-design process. Subsequently, a matching and comparing of the two investigations allows identifying gaps and deriving a broad combination set. A clustering of the criteria found should provide systematized access to the set. 


\section{METHODOLOGY}

The Design Research Methodology (DRM) according to Blessing and Chakrabarti (2009) provides the methodological framework for research within this paper. The type of research chosen is type 2, including a review-based research clarification within Sections (Sec.) 1 to 3 (i.e. first step of DRM). Descriptive Study I (2nd DRM step; not performed comprehensively in this case, rather review-based) is then conducted as a systematic literature review to answer the following research question: Which criteria influence lightweight design and which criteria are used to derive lightweight potential? The detailed procedure, including all constraints, is illustrated in Section 4. Subsequently, for the initial prescriptive study in Section 5, a comparison of both criteria sets is conducted. The transfer of criteria influencing lightweight design (set 1 found in literature) missing from the set of criteria used to derive lightweight design (set 2 found in literature) constitutes a concept sheet (third step of DRM), which functions as a comprehensive set for deriving lightweight potential. Furthermore, it can serve as a basis for designers to choose the appropriate sub-set of criteria for a particular lightweight-design application. Figure 1 illustrates the entire procedure followed within this paper.

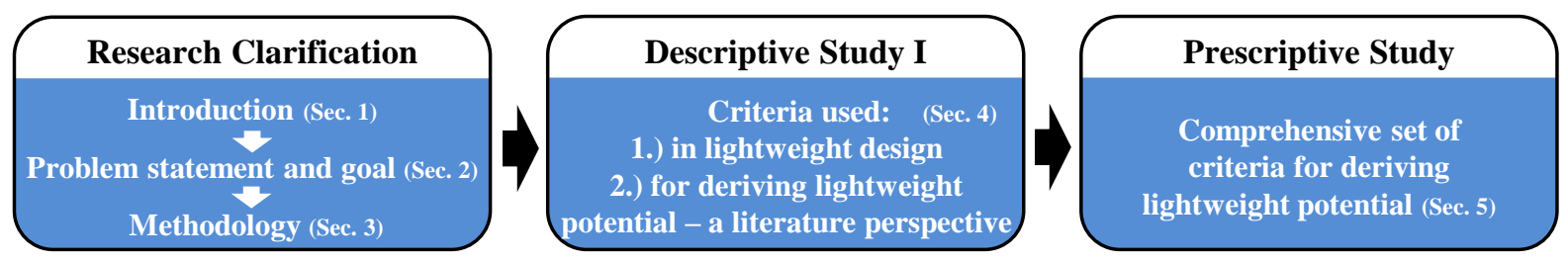

Figure 1. Procedure followed in this paper for elaborating criteria for lightweight potential

\section{CRITERIA USED FOR BOTH LIGHTWEIGHT DESIGN AND THE DERIVA- TION OF LIGHTWEIGHT POTENTIAL - A LITERATURE PERSPECTIVE}

To gain an insight into the way in which criteria for lightweight design are viewed in literature, the procedure of the systematic literature review is presented in this section. In the first subsection (4.1), the focus is on the procedure for identifying criteria for lightweight design, while the second subsection (4.2) focuses on the criteria for deriving lightweight potential.

\subsection{Criteria for lightweight design}

Initially, the following procedure was planned in order to perform the systematic literature review. It is subdivided into four basic steps:

1. Initial examination of relevant synonyms of the terms "criterion" and "lightweight design".

2. Execution of the actual review in four indexed, electronic databases with the relevant synonyms identified in (1.).

3. Initial selection of the papers found in step (2.).

4. Detailed analysis of the selection in step (3.).

The results of this four-step procedure are illustrated in Section 5.

To begin with, a list of synonyms for the term "criterion" and the term "lightweight design" were defined based on an initial investigation of papers with high relevance for lightweight design. As can be seen in Table 1, seven synonyms for the term "criterion" and eight synonyms for the term "lightweight design" were used in both singular and plural form.

Table 1. Relevant synonyms for the terms "criterion" and "lightweight design"

\begin{tabular}{ll} 
Synonyms for the te rm "crite rion*" & Synonyms for the te rm "lightweight design*" \\
"Parameter" (Delogu et al., 2018) & "Lightweight construction" (Schleinkofer et al., 2018) \\
\hline "Indicator" (Choudry et al., 2018) & "Lightweight development" (defined by the authors) \\
\hline "Factor" (Hottle et al., 2017) & "Lightweight engineering" (Caldwell et al., 2013) \\
\hline "Basis" (Koffler and Rohde-Brandenburger, 2010) & "Lightweight optimization" (Wang et al., 2017) \\
\hline "Measure" (Delogu et al., 2016) & "Mass reduction" (Hottle et al., 2017) \\
\hline "Multi-objective" (Wang et al., 2017) & "Mass saving" (Qin et al., 2016) \\
\hline "Multi-criteria" (Kaspar et al., 2018) & "Weight reduction" (Viqaruddin and Reddy., 2017) \\
\hline & "Weight saving" (defined by the authors) \\
\hline
\end{tabular}


Additionally, in order to achieve more relevant results, the term "lightweight design" and its synonyms were searched in the title of the respective papers. This was to ensure that the main focus of the publications found was on lightweight design in order to gather more relevant criteria. By setting this limitation, the number of search hits could be reduced by a factor of up to 15 (depending on the database) in comparison to targeting the title and abstract and keywords. The search string was then complemented by an additional field with the term "criterion" and its synonyms, which were searched for within the full publications. The described search strings were used in four indexed, electronic literature databases to conduct the actual literature review: Science Direct, Web of Science, Pro Quest and Engineering Village. The search itself was conducted during September and October 2018.

Filters were used to narrow down the search results. Firstly, only papers published between 1980 and the present were taken into account. Secondly, filters were used to focus exclusively on conference articles and journal articles. Furthermore, filters were set individually according to the database's structure to include only papers related to engineering design (mechanical, energy, civil, environmental, etc.) in the broadest sense. The numbers of search hits are shown in Figure 2 (left). In the final step, the 465 papers found were examined in more detail, which entailed analyzing the title, abstract and keywords following the sequence of requirements below:

- Relevance to lightweight design

- References/information on motivation for lightweight design

- References/information on criteria for capturing different motivations for lightweight design
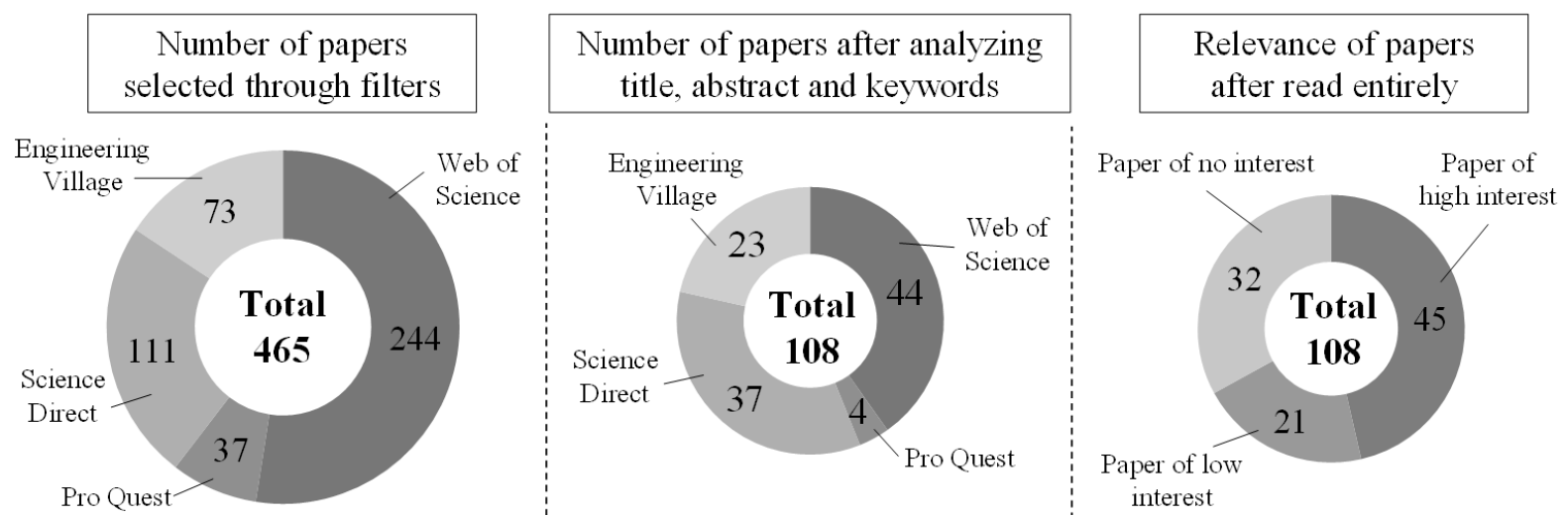

Figure 2. Papers with references to criteria for lightweight design

After this more detailed investigation, 108 papers remained to be analyzed in their entirety according to information on criteria for lightweight design (Figure 2, center). 4 papers were found on both Science Direct and Web of Science, while 6 papers were found on both Science Direct and Engineering Village. Finally, the relevance of the papers found was assessed based on the distinct criteria identified (Figure 2, right).

\subsection{Criteria for deriving lightweight potential}

The basic procedure for searching for criteria for deriving lightweight potential was the same as described in Section 4.1 for lightweight-design criteria. Synonyms for the term "lightweight potential" were thus identified (see Table 2) and searched for in the full papers. The four electronic databases and the filters were set as in Subsection 4.1.

Table 2. Relevant synonyms for the term "lightweight potential"

\begin{tabular}{ll}
\multicolumn{2}{c}{ Synonyms for the term "lightweight potential"”" } \\
\hline "Lightweight-design potential" (Albers et al., 2017) & "Mass-saving potential" (Caldwell et al., 2013) \\
\hline "Lightweight-construction potential" (defined by the authors) & "Weight-reduction potential" (Hottle et al., 2017) \\
\hline "Mass-reduction potential" (Kroll et al., 2011) & "Weight-saving potential" (Luedeke and Vielhaber, 2014) \\
\hline
\end{tabular}

The 663 papers identified - shown in Figure 3 (left) - were then analyzed in detail with regard to the title, abstract and keywords following the sequence of requirements:

- Relevance to lightweight design and corresponding mass-/weight-reduction methods

- References/information on special methods for deriving lightweight potential

- References/information on criteria used within these methods 
This procedure revealed 64 papers to be relevant (Figure 3, center) in terms of criteria used for deriving lightweight potential. Only one paper was found on several platforms. Lastly, the relevance of the papers found was assessed based on the distinct criteria identified (Figure 3, right).
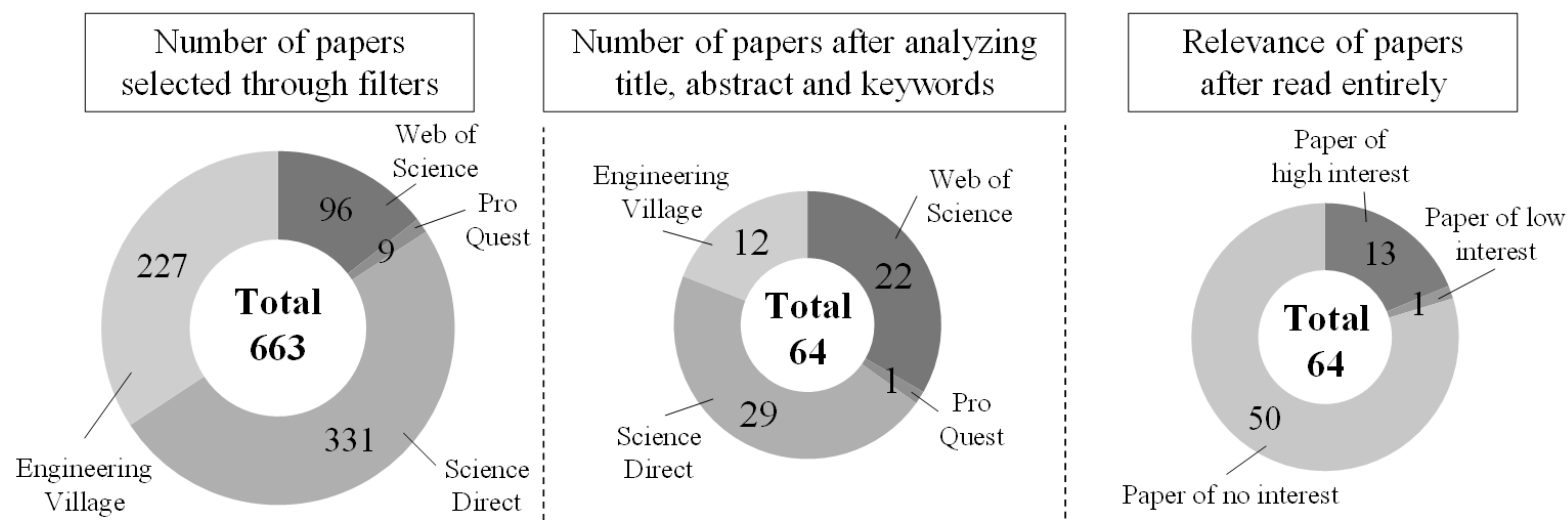

Figure 3. Papers with references to criteria for identifying lightweight potential

\section{SET OF CRITERIA FOR IDENTIFYING LIGHTWEIGHT POTENTIAL WITH A BROAD SCOPE}

The analysis performed in the previous section enables the results to be summarized and clustered. The overarching aim of this section is to compare the criteria found for lightweight design and for deriving lightweight potential before identifying any gaps. Furthermore, building upon these gaps, the aim is to specify a broader and more holistic set of criteria for deriving lightweight potential.

Overall, 14 different criteria used in lightweight design were found in the 45 relevant papers (Table 3, top 14 rows) mentioned in Section 4.1. In order to cluster these different criteria, the papers analyzed in detail were screened for different potential clustering dimensions. Lifecycle engineering is one method for addressing different dimensions. Three dimensions used in this context proved sufficient for lightweight-design applications (Kaspar et al., 2018), thus enabling the criteria found to be clustered. The dimensions consider economic, ecological and technological issues of an engineering solution and help to weight the various factors, such as with regard to the material-selection process (Peças et al., 2014). Most criteria found could be assigned precisely to one dimension, while some were placed between the economic and ecological dimensions because they could be assigned to both (Table 3, top left, indicated by double arrow).

Below, some of the criteria found will be briefly discussed. Concerning the technological dimension, most lightweight-design cases deal with reducing mass while improving the structural performance. This can be traced back to Maxwell (1869), who investigated optimized topology structures theoretically. Since this paper focuses on "motivational criteria" for lightweight design, papers dealing exclusively with structural performance improvements (e.g. bionics for engineering) were not considered. However, if papers contained significant criteria and (additionally) structural performance criteria, this was recorded. The criterion which appeared most frequently (16 hits) in this dimension was improve working performance; either to improve the acceleration of a production machine (inter alia Schleinkofer et al., 2018), to improve the handling of a product or the ergonomics of a prosthesis (Ahn et al., 2017). When improving performance by reducing the mass of a product, lightweight design usually comes with higher costs, which are tolerated to a certain extent (Friedrich, 2017). With regard to the ecological dimension, the focus is noticeably on reduce greenhouse-gas emissions $(G H G)$. A differentiation is made between emissions exclusively during the usage phase (11 hits) and during the entire lifecycle (9 hits). According to Hottle et al. (2017), for instance, the usage phase of a vehicle remains the phase which accounts for $84-88 \%$ of the GHG emissions. Together with the most significant hit (33) increase fuel efficiency/reduce operational energy, these criteria reflect the effort expended to make the certain product vehicle more environmentally friendly (Delogu et al., 2018).

This trend can also be observed in Figure 4. The papers found on criteria for lightweight design disproportionally (over 50\%) concerned the automotive industry. In the last dimension (economic criteria), the criterion reduce manufacturing costs (17 hits) also originated from this industry, thus illustrating the high cost pressure faced by car manufacturers (Mayyas et al., 2017).

Moreover, some criteria influence each other, e.g. the increase secondary mass savings and the increase of the fuel efficiency. This has to be investigated in further research. 
Table 3. Set of criteria for lightweight design

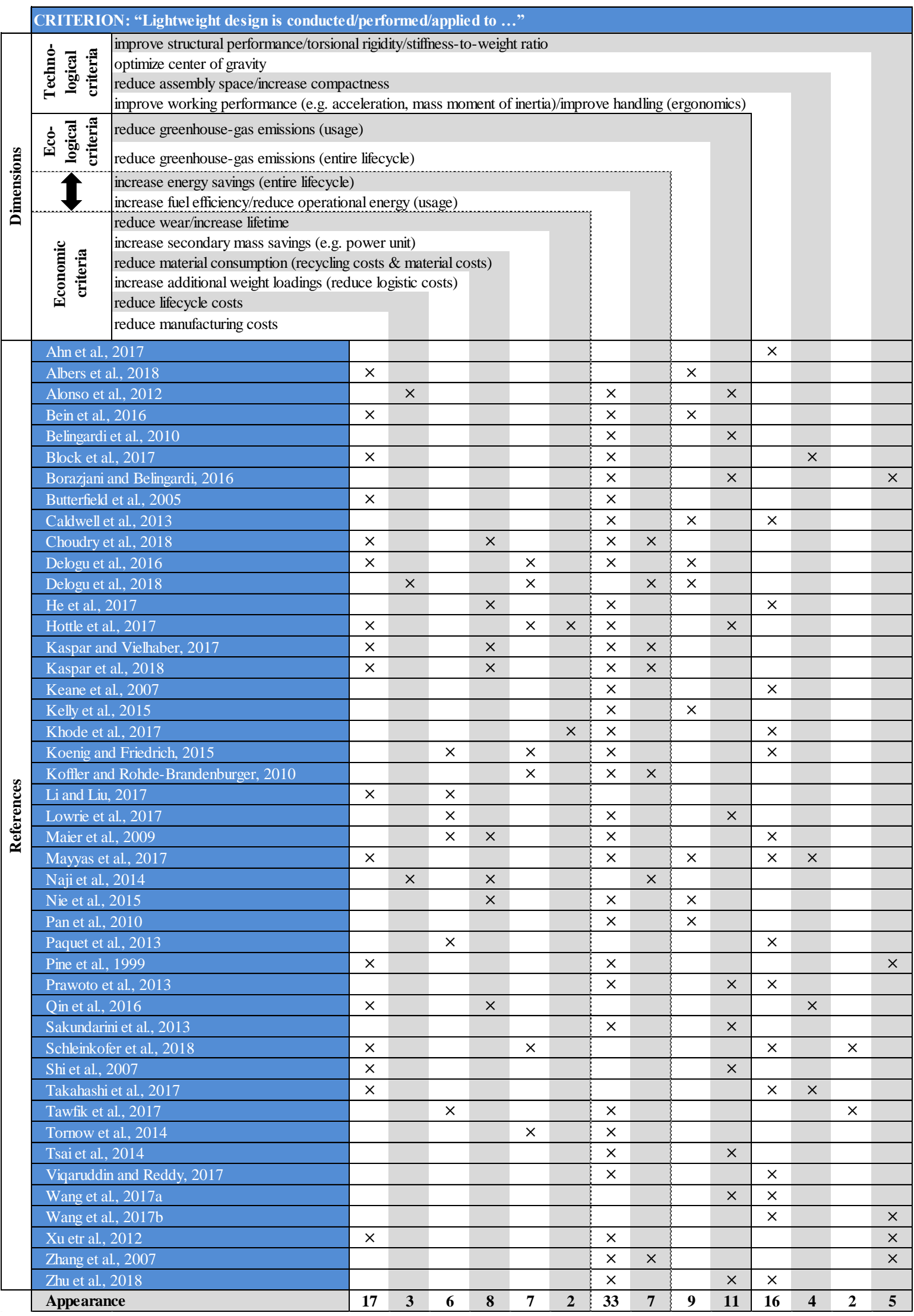

At this point, it should be mentioned that the systematic literature study is subject to limits regarding its holistic nature. The derived criteria set (Tables 3 and 4) makes no claim to being exhaustive. Further investigations (e.g. in fundamental books for lightweight design) will need to address the evaluation of the criteria found, in addition to expanding the set. 


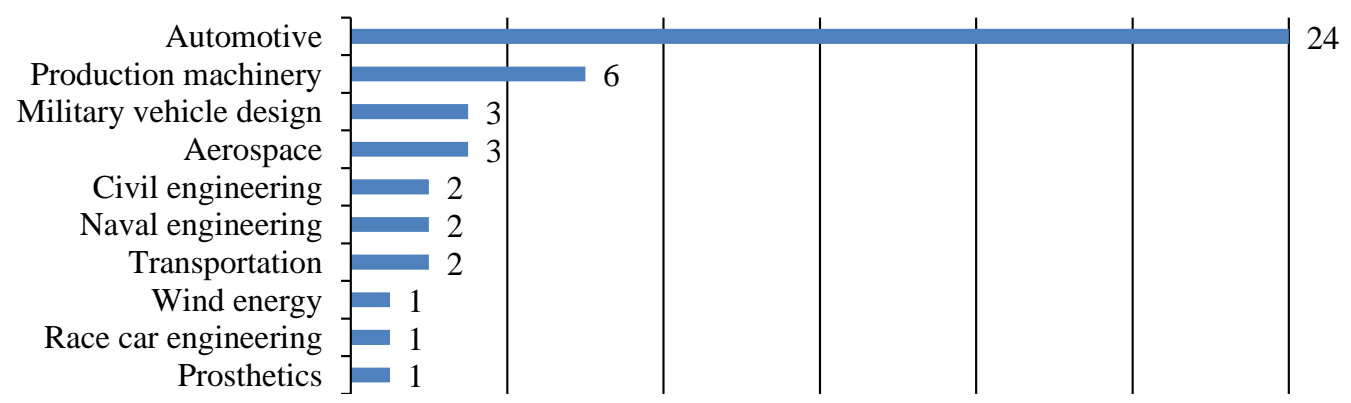

Figure 4. Distribution of papers sorted by industry

The second part of the literature review focused on the criteria for deriving lightweight potential. The methods actually used for deriving lightweight potential are numerous, although the paper's framework does not allow these methods to be investigated in detail. In order to be able to compare both criteria sets, the criteria for deriving lightweight potential found within the 13 relevant papers were listed in Table 4, which already included the criteria for lightweight design previously found in order to simplify comparison.

Table 4. Criteria used for deriving lightweight potential

CRITERION: "Lightweight design is conducted/performed/applied to ..."

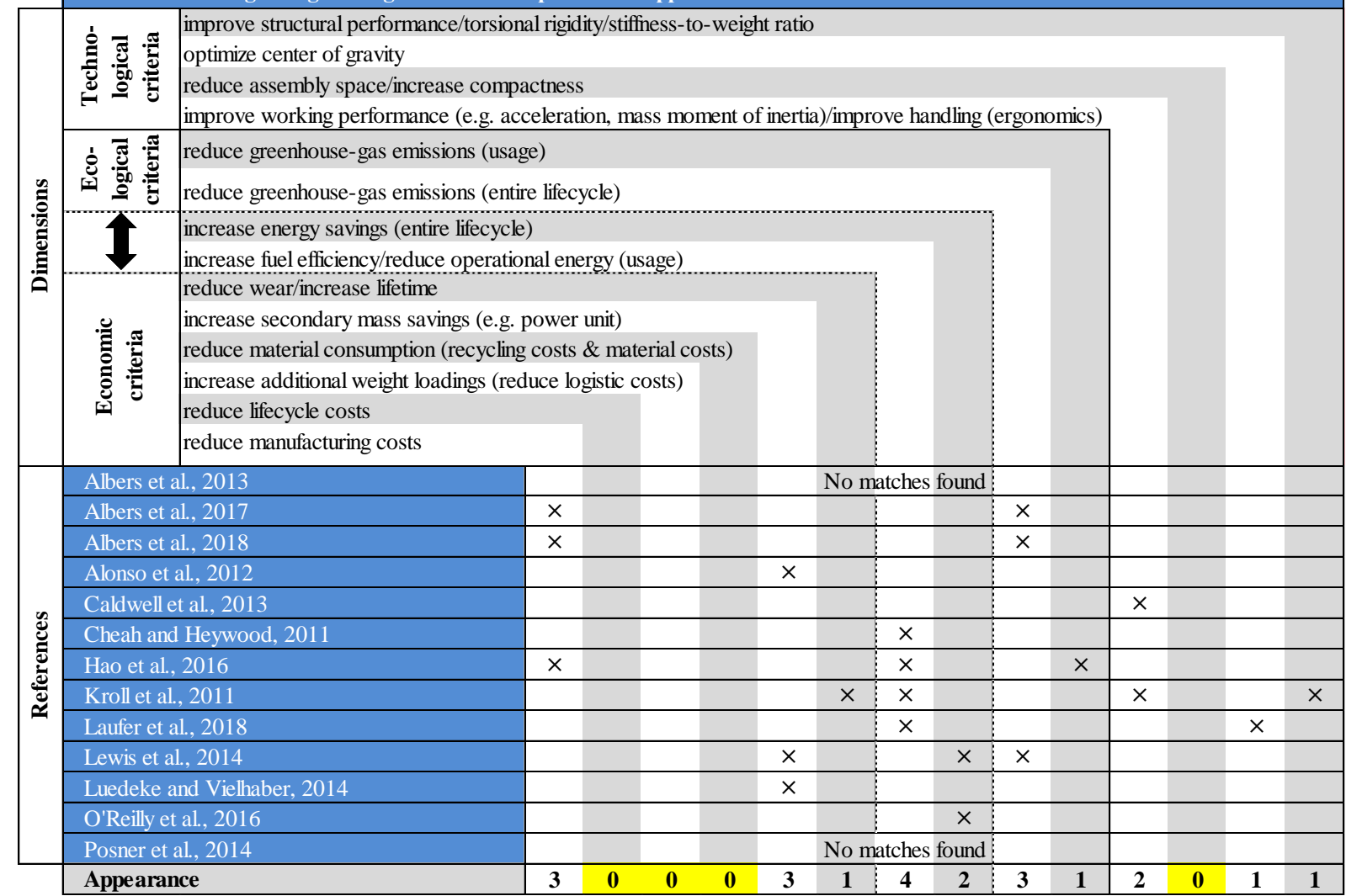

Firstly, it can be observed that papers in Table 4 which contain criteria for deriving lightweight potential exhibit the most important criteria (reduce manufacturing costs [3 hits], increase fuel efficiency/reduce operational energy [4 hits], reduce greenhouse-gas emissions [3 hits]) when compared to the appearance of the criteria in Table 3. This can be explained through the high relevance of methods dealing with these criteria in the automotive and production-machinery industry (context of 9 out of 12 papers). Secondly, four criteria (reduce lifecycle costs, increase additional weight loadings, reduce material consumption, reduce assembly space) did not appear in any papers with regard to deriving lightweight potential (marked in Table 4, last row). Thirdly, some of the methods found within the papers take other additional criteria into account, such as functional importance (Albers et al., 2013; Caldwell et al., 2013), customer requirements (Posner et al., 2014) and material composition (Lewis et al., 2014). Three papers appeared in both reviews (Albers et al., 2018; Caldwell et al., 2013; Alonso et al., 2012). 


\section{CRITICAL DISCUSSION AND OUTLOOK}

The investigation within this paper revealed several issues concerning the criteria used for deriving lightweight potential. On the one hand, different motivations for conducting lightweight design lead to different criteria regarding the lightweight potential derived. These motivations are spread over different industries with different emphases. On the other hand, proving the hypothesis from Section 2, a gap was identified between important criteria in lightweight design and the criteria used for deriving lightweight potential. This gap especially concerns cost considerations (lifecycle, logistics, material consumption, Table 4), which can be targeted using methods from other fields such as "target costing" (Ibusuki and Kaminski, 2007) or "life cycle costing" (Woodward, 1997), which are already used in engineering contexts. The main issue here seems to be the selection of appropriate methods for dealing with the various criteria. Conflicting criteria (e.g. manufacturing cost vs. improved performance) pose a particular challenge when methodologically assessing lightweight potential. Furthermore, a decision must be made on whether or not to combine existing methods to capture all relevant criteria for a particular lightweight-design case, or to seek new methods for performing the assessment. Methods from different fields such as management science can yield significant benefits when evaluating lightweight potential with a broad scope. Nevertheless, the broad set of criteria derived enables designers to choose the most representative criteria for a particular design case, thus leading to a more comprehensible derivation of lightweight potential. The set also forms a basis for designers and design teams to refine their understanding of their own motivations for conducting lightweight design. This might help to steer lightweight-design efforts in the most effective direction.

Future work will focus on the assessment and/or development of methods enabling lightweight potential to be derived from all relevant criteria and will deliver a framework for selecting the appropriate methods for a particular lightweight-design scenario. Additionally, the criteria found will be evaluated with experts on lightweight design from different industrial fields to contribute to the question of whether or not the derived criteria set is useful.

\section{REFERENCES}

Ahn, H.-J., Lee, K.-H. and Lee, C.-H. (2017), "Design optimization of a knee joint for an active transfemoral pros-thesis for weight reduction”, Journal of Mechanical Science and Technology, Vol. 31 No. 12, pp. 5905-5913.

Albers, A., Wagner, D., Ruckpaul, A., Hessenauer, B., Burkardt, N. and Matthiesen, S. (2013), "Target Weighing- A New Approach for Conceptual Lightweight Design in Early Phases of Complex Systems Development", Proceedings of the ICED 2013 / 19th International Conference on Engineering Design, Seoul, Korea, August 19-22, 2013, pp. 301-310.

Albers, A., Revfi, S. and Spadinger, M. (2017), "Extended Target Weighing Approach - Identification of Lightweight Design Potential for New Product Generations", Proceedings of the ICED 2017 / 21th International Conference on Engineering Design, Vancouver, USA, August 21-25, 2017, pp. 367-376.

Albers, A., Moeser, G. and Revfi, S. (2018), "Synergy effects by using sysml models for the lightweight design method "extended target weighing approach", Procedia CIRP, Vol. 70, pp. 434-439.

Alonso, E., Lee, T.M., Bjelkengren, C., Roth, R. and Kirchain, R.E. (2012), "Evaluating the potential for secondary mass savings in vehicle lightweighting", Environmental science \& technology, Vol. 46 No. 5 , pp. 2893-2901.

Bein, T., Mayer, D., Hagebeuker, L., Bachinger, A., Bassan, D., Pluymers, B. and Delogu, M. (2016), "Enhanced lightweight design - first results of the FP7 project ENLIGHT", Transportation Research Procedia, Vol. 14, pp. 1031-1040.

Belingardi, G., Chiandussi, G., Gobetto, E. and Scattina, A. (2010), "Bonnet weight reduction and VRU protection. Design proposals implementing non-conventional materials", International Journal of Automotive Technology, Vol. 11 No. 6, pp. 831-842.

Blessing, L.T.M. and Chakrabarti, A. (2009), DRM, a Design Research Methodology, Springer, London. https://doi.org/10.1007/978-1-84882-587-1.

Block, P., Schlueter, A., Veenendaal, D., Bakker, J., Begle, M., Hischier, I., Hofer, J., Jayathissa, P., Maxwell, I., Echenagucia, T.M., Nagy, Z., Pigram, D., Svetozarevic, B., Torsing, R., Verbeek, J., Willmann, A. and Lydon, G.P. (2017), "NEST HiLo. Investigating lightweight construction and adaptive energy systems", Journal of Building Engineering, Vol. 12, pp. 332-341.

Borazjani, S. and Belingardi, G. (2016), "Lightweight design. Detailed comparison of roof panel solutions at crash and stiffness analyses", International Journal of Crashworthiness, Vol. 22 No. 1, pp. 49-62.

Butterfield, J., Yao, H., Price, M., Armstrong, C. and Raghunathan, S. (2005), "Weight reduction methodologies for a thrust reverser cascade using aerodynamic and structural integration", Proceedings of the Institution of Mechanical Engineers, Part G: Journal of Aerospace Engineering, Vol. 218 No. 5, pp. 301-313. 
Caldwell, B.W., Namouz, E.Z., Richardson, J.L., Sen, C., Rotenburg, T., Mocko, G.M., Summers, J.D. and Obieglo, A. (2013), "Automotive lightweight engineering. A method for identifying lazy parts", International Journal of Vehicle Design, Vol. 63 No. 4, p. 364.

Cheah, L. and Heywood, J. (2011), "Meeting U.S. passenger vehicle fuel economy standards in 2016 and beyond", Energy Policy, Vol. 39 No. 1, pp. 454-466.

Choudry, S.A., Kaspar, J., Alber, U. and Landgrebe, D. (2018), "Integration of an assessment methodology for the selection of joining technologies in lightweight engineering", Procedia CIRP, Vol. 70, pp. 217-222.

Delogu, M., Del Pero, F. and Pierini, M. (2016), "Lightweight design solutions in the automotive field. Environmental modelling based on fuel reduction value applied to diesel turbocharged vehicles", Sustainability, Vol. 8 No. 11, p. 1167.

Delogu, M., Zanchi, L., Dattilo, C.A. and Ierides, M. (2018), "Parameters affecting the sustainability tradeoff been production and use stages in the automotive lightweig ht design", Procedia CIRP, Vol. 69, pp. 534-539.

Friedrich, H. E. (2017), Leichtbau in der Fahrzeugtechnik, Springer Vieweg Verlag, Wiesbaden.

Hao, H., Wang, S., Liu, Z. and Zhao, F. (2016), “The impact of stepped fuel economy targets on automaker's light-weighting strategy. The China case”, Energy, Vol. 94, pp. 755-765.

He, Y., Huang, T., Wang, Y., Nie, Y., Li, Y. and Wang, Y. (2017), “A new lightweight design method integrating shape optimization with life cycle assessment for extrusion dies", Journal of Cleaner Production, Vol. 150, pp. 47-57.

Hottle, T., Caffrey, C., McDonald, J. and Dodder, R. (2017), "Critical factors affecting life cycle assessments of material choice for vehicle mass reduction”, Transportation Research Part D: Transport and Environment, Vol. 56, pp. 241-257.

Ibusuki, U. and Kaminski, P. C. (2007), "Product development process with focus on value engineering and target-costing: A case study in an automotive company: Scheduling in batch-processing industries and supply chains", International Journal of Production Economics, Vol. 105 No. 2, pp. 459-474.

Naji, S., Çelik, O.C., Johnson Alengaram, U., Jumaat, M.Z. and Shamshirband, S. (2014), "Structure, energy and cost efficiency evaluation of three different lightweight construction systems used in low-rise residential buildings", Energy and Buildings, Vol. 84, pp. 727-739.

Keane, R.G., Scher, R.M. and Piskorski, R. (2007), "Toward a lightweight design philosophy for high-speed sealift ships", Naval Engineers Journal, Vol. 119 No. 4, pp. 37-63.

Kaspar, J. and Vielhaber, M. (2017), "Sustainable lightweight design - relevance and impact on the product development \& lifecycle process”, Procedia Manufacturing, Vol. 8, pp. 409-416.

Kaspar, J., Choudry, S.A. and Vielhaber, M. (2018), "Concurrent selection of material and joining technology holistically relevant aspects and its mutual interrelations in lightweight engineering", Procedia CIRP, Vol. 72, pp. 780-785.

Kelly, J.C., Sullivan, J.L., Burnham, A. and Elgowainy, A. (2015), "Impacts of vehicle weight reduction via material substitution on life-cycle greenhouse gas emissions", Environmental Science \& Technology, Vol. 49 No. 20, pp. 12535-12542.

Khode, A.P., Senthilkumar, K., Patil, B.S., Kulkarni, N. and Trikande, M.W. (2017), "Shape optimization and weight reduction of seat structure for wheeled armoured amphibious combat vehicle", Materials Today: Proceedings, Vol. 4 No. 2, pp. 1917-1926.

Koenig, J. and Friedrich, H.E. (2011), "Integral consideration of the lightweight design for railway vehicles", In: Conference Proceedings. Young Researchers Seminar, June, 8-10, 2011, Copenhagen, Denmark.

Koffler, C. and Rohde-Brandenburger, K. (2010), "On the calculation of fuel savings through lightweight design in automotive life cycle assessments”, The International Journal of Life Cycle Assessment, Vol. 15 No. 1, pp. $128-135$.

Kroll, L., Blau, P., Wabner, M., Frieß, U., Eulitz, J. and Klärner, M. (2011), "Lightweight components for energyefficient machine tools", CIRP Journal of Manufacturing Science and Technology, Vol. 4 No. 2, pp. 148-160.

Laufer, F., Roth, D. and Binz, H. (2018), "Supporting engineers in lightweight design: The Energy Distribution Analysis (EDA)", in 15th International Design Conference, May, 21-24, 2018, Croatia; The Design Society, Glasgow, UK, pp. 829-840.

Lewis, A.M., Kelly, J.C. and Keoleian, G.A. (2014), "Vehicle lightweighting vs. electrification. Life cycle energy and GHG emissions results for diverse powertrain vehicles", Applied Energy, Vol. 126, pp. 13-20.

Li, A. and Liu, C. (2017), "Lightweight design of a crane frame under stress and stiffness constraints using super-element technique", Advances in Mechanical Engineering, Vol. 9 No. 8, pp. 168781401771662.

Lowrie, J., Pang, H. and Ngaile, G. (2017), "Weight reduction of heavy-duty truck components through hollow geometry and intensive quenching”, Journal of Manufacturing Processes, Vol. 28, pp. 523-530.

Luedeke, T. and Vielhaber, M. (2014), "Holistic Approach for Secondary Weight Improvements", Procedia CIRP, Vol. 21, pp. 218-223.

Maxwell, C. (1869), Scientific papers II, University Press, Cambridge.

Maier, J.R.A., McLellan, J.M., Mocko, G., Fadel, G.M. and Brudnak, M. (2009), "Lightweight Engineering of Military Vehicles Through Requirements Analysis and Function Integration”, In: ASME International 
Design Engineering Technical Conferences and Computers and Information in Engineering Conference. August 30-September 2, 2009, San Diego, California, USA.

Mayyas, A., Omar, M., Hayajneh, M. and Mayyas, A.R. (2017), "Vehicle's lightweight design vs. electrification from life cycle assessment perspective", Journal of Cleaner Production, Vol. 167, pp. 687-701.

Nie, Y., Lin, Y.-J., Sun, W. and Huang, T. (2015), “A Methodology for Optimal Lightweight Design of Moulds and Dies: A Case Study”, In: Proceedings of the ASME International Mechanical Engineering Congress and Exposition - 2015, November 13-15, Houston, Texas, USA.

O’Reilly, C.J., Göransson, P., Funazaki, A., Suzuki, T., Edlund, S., Gunnarsson, C., Lundow, J.-O., Cerin, P., Cameron, C.J., Wennhage, P. and Potting, J. (2016), "Life cycle energy optimisation. A proposed methodology for integrating environmental considerations early in the vehicle engineering design process", Journal of Cleaner Production, Vol. 135, pp. 750-759.

Pan, F., Zhu, P. and Zhang, Y. (2010), "Metamodel-based lightweight design of B-pillar with TWB structure via support vector regression”, Computers \& Structures, Vol. 88 No. 1-2, pp. 36-44.

Paquet, R., Lebaillif, D. and Petitpas, E. (2013), "Use of multi-scale approach for vehicle weight reduction study", Procedia Engineering, Vol. 66, pp. 403-414.

Peças P, Ribeiro I, Folgado R, Henriques E. (2009), “A life cycle engineering model for technology selection: a case study on plastic injection moulds for low production volumes”, J Clean Prod, Vol. 17 No. 9, pp. 846-856.

Pine, T., Lee, M.M.K. and Jones, T.B. (1999), "Weight reduction in automotive structures - an experimental study on torsional stiffness of box sections", Proceedings of the Institution of Mechanical Engineers, Part D: Journal of Automobile Engineering, Vol. 213 No. 1, pp. 59-71.

Posner, B., Binz, H., Roth, D. and others. (2014), "Supporting Lightweight Design Potential Assessment in the Conceptual Phase", Marjanović, D., Štorga, M., Pavković, N. and Bojčetić, N. (Eds.), In: Proceedings of the DESIGN 2014, 13th International Design Conference. Zagreb, Croatia; The Design Society, Glasgow, UK, pp. 353-362.

Prawoto, Y., Djuansjah, J., Tawi, K.B. and Fanone, M.M. (2013), “Tailoring microstructures. A technical note on ecofriendly approach to weight reduction through heat treatment", Materials \& Design, Vol. 50, pp. 635-645.

Qin, C., Innes-Wimsatt, E. and Loth, E. (2016), "Hydraulic-electric hybrid wind turbines. Tower mass saving and energy storage capacity", Renewable Energy, Vol. 99, pp. 69-79.

Sakundarini, N., Taha, Z., Abdul-Rashid, S.H. and Ghazila, R.A.R. (2013), "Optimal multi-material selection for lightweight design of automotive body assembly incorporating recyclability”, Materials \& Design, Vol. 50 , pp. 846-857.

Schleinkofer, U., Laufer, F., Zimmermann, M., Roth, D. and Bauernhansl, T. (2018), "Resource-efficient manufacturing systems through lightweight construction by using a combined development approach", Procedia CIRP, Vol. 72, pp. 856-861.

Shi, Y., Zhu, P., Shen, L. and Lin, Z. (2007), "Lightweight design of automotive front side rails with TWB concept", Thin-Walled Structures, Vol. 45 No. 1, pp. 8-14.

Soanes, C. and Persall, J. (Eds.) (2005), Oxford dictionary of English, 2. ed., rev, Oxford Univ. Pr, Oxford.

Takahashi, T., Takemoto, M., Ogasawara, S., Hino, W. and Takezaki, K. (2017), "Size and Weight Reduction of an In-Wheel Axial-Gap Motor Using Ferrite Permanent Magnets for Electric Commuter Cars", IEEE Transactions on Industry Applications, Vol. 53 No. 4, pp. 3927-3935.

Tawfik, B.E., Leheta, H., Elhewy, A. and Elsayed, T. (2017), "Weight reduction and strengthening of marine hatch covers by using composite materials", International Journal of Naval Architecture and Ocean Engineering, Vol. 9 No. 2, pp. 185-198.

Tornow, A., Raatz, A. and Dröder, K. (2014), "Battery system development - assembly planning between lightweight design and high volume production", Procedia CIRP, Vol. 23, pp. 143-148.

Tsai, W.-H., Chang, Y.-C., Lin, S.-J., Chen, H.-C. and Chu, P.-Y. (2014), “A green approach to the weight reduction of aircraft cabins", Journal of Air Transport Management, Vol. 40, pp. 65-77.

Viqaruddin, M. and Ramana Reddy, D. (2017), "Structural optimization of control arm for weight reduction and improved performance", Materials Today: Proceedings, Vol. 4 No. 8, pp. 9230-9236.

Wang, D., Lv, T., Wang, C., Zhang, C., Wang, F. and Zhang, W. (2017a), "Multi-objective lightweight optimization and design for body-in-white frontal sub-module", Proceedings of the Institution of Mechanical Engineers, Part D: Journal of Automobile Engineering, Vol. 232 No. 11, pp. 1465-1480.

Wang, M., Liu, H. and Huang, T. (2017b), “An approach for the lightweight design of a 3-SPR parallel mechanism", Journal of Mechanisms and Robotics, Vol. 9 No. 5, p. 51016.

Woodward, D.G. (1997), "Life cycle costing-theory, information acquisition and application”, International Journal of Project Management, Vol. 15 No. 6, pp. 335-344.

Xu, D., Chen, J., Tang, Y. and Cao, J. (2012), “Topology optimization of die weight reduction for high-strength sheet metal stamping”, International Journal of Mechanical Sciences, Vol. 59 No. 1, pp. 73-82.

Zhang, Y., Zhu, P. and Chen, G. (2007), "Lightweight design of automotive front side rail based on robust optimisation", Thin-Walled Structures, Vol. 45 No. 7-8, pp. 670-676.

Zhu, L., Li, N. and Childs, P. (2018), "Light-weighting in aerospace component and system design", Propulsion and Power Research, Vol. 7 No. 2, pp. 103-119. 